\title{
Eficiência do uso da radiação solar e índices morfofisiológicos em cultivares de feijoeiro ${ }^{1}$
}

\author{
Gisele Carneiro da Silva Teixeira ${ }^{2}$, Luís Fernando Stone ${ }^{3}$, Alexandre Bryan Heinemann ${ }^{3}$
}

\begin{abstract}
Solar radiation use efficiency and morphophysiological indices in common bean cultivars

Common bean crops present a broad edaphoclimatic adaptation, allowing their cultivation throughout the year. However, in order to reach good economic income levels, it is fundamental to understand the processes that affect the growth and development of the crop in various environments. This study aimed to compare two common bean cultivars (BRS Radiante and Pérola) contrasting in cycle and growth behavior by using morphophysiological indices and solar radiation use efficiency. The following traits were evaluated: light extinction coefficient, radiation use efficiency, phenologic development, leaf area index, total dry matter weight, crop growth rate, relative growth rate and dry matter partitioning. The BRS Radiante cultivar shows a higher vigor, when compared to the Pérola cultivar, due to its faster initial phenologic development and higher initial and relative growth rates. Both cultivars differ for leaf area index and shoot architecture, although that does not happen for light extinction coefficient. The BRS Radiante cultivar shows a higher solar radiation use efficiency, resulting in a greater dry matter yield throughout its development.
\end{abstract}

KEY-WORDS: Phaseolus vulgaris L.; ecophysiology; plant growth analysis.

\section{INTRODUÇÃO}

O crescimento e desenvolvimento do feijoeiro são afetados por diversos fatores de origem biótica, como a ocorrência de pragas e doenças, e abiótica, como os elementos climáticos, condições químicas e físicas do solo. Dentre esses fatores, o conhecimento do efeito do clima na cultura pode auxiliar no planejamento agrícola, possibilitando a obtenção de maiores produtividades e diminuição de perdas por fatores climáticos (Pereira et al. 2014).

\section{RESUMO}

A cultura do feijoeiro apresenta ampla adaptação edafoclimática, o que permite o seu cultivo durante todo o ano. Contudo, para obterem-se bons patamares de rendimento econômico, é fundamental compreender os processos que afetam o crescimento e desenvolvimento da cultura, em diversos ambientes. Este estudo objetivou comparar duas cultivares de feijoeiro (BRS Radiante e Pérola), contrastantes no ciclo e hábito de crescimento, por meio de índices morfofisiológicos e eficiência de uso da radiação solar. Determinaram-se as seguintes características: coeficiente de extinção de luz, eficiência no uso da radiação, desenvolvimento fenológico, índice de área foliar, massa de matéria seca total, taxa de crescimento da cultura, taxa de crescimento relativo e partição da massa de matéria seca. A cultivar BRS Radiante apresenta maior vigor, quando comparada à cultivar Pérola, devido ao desenvolvimento fenológico inicial mais rápido e maiores taxas de crescimento inicial e relativo. As cultivares não diferem quanto ao coeficiente de extinção de luz, embora apresentem diferença quanto ao índice de área foliar e arquitetura da parte aérea. A cultivar BRS Radiante apresenta maior eficiência de uso da radiação solar, resultando em maior produção de matéria seca ao longo do seu desenvolvimento.

PALAVRAS-CHAVE: Phaseolus vulgaris L.; ecofisiologia; análise de crescimento vegetal.

A radiação fotossinteticamente ativa é um dos fatores climáticos que tem influência direta sobre o crescimento e desenvolvimento da cultura do feijoeiro, uma vez que está diretamente relacionada com a taxa fotossintética das plantas (Procópio et al. 2003). Seu uso efetivo pelas plantas depende, além de sua disponibilidade, da capacidade delas de interceptá-la em seu dossel. Essa interceptação ocorre com a atenuação da luz no dossel da planta, que varia de acordo com suas características morfológicas, como o índice de área foliar e arranjo e inclinação das folhas, em relação à luz incidente (Ruiz \& Bertero 2008).

1. Trabalho recebido em fev./2014 e aceito para publicação em jan./2015 (http://dx.doi.org/10.1590/1983-40632015v4528297).

2. Universidade Federal de Goiás (UFG), Escola de Agronomia, Goiânia, GO, Brasil. E-mail: gisele.agronomia@hotmail.com.

3. Empresa Brasileira de Pesquisa Agropecuária (Embrapa Arroz e Feijão), Santo Antônio de Goiás, GO, Brasil.

E-mails: luis.stone@embrapa.br, alexandre.heinemann@embrapa.br. 
Dessa forma, a diferença de morfologia das plantas de cultivares com hábito de crescimento contrastante pode interferir na extinção da luz no seu dossel e, consequentemente, na quantidade de radiação fotossinteticamente ativa interceptada e absorvida pelas folhas. Tais combinações afetam a eficiência de conversão da energia radiante em energia química pela fotossíntese e, portanto, há efeitos diretos na produção de biomassa pelas culturas (Fagundes et al. 2001).

As cultivares de porte ereto, característica do hábito de crescimento determinado (tipo I), geralmente apresentam maior taxa fotossintética que as de hábito de crescimento indeterminado (tipo III), mais prostradas, e essa é a variável que mais afeta a eficiência de uso da radiação solar (Sinclair \& Muchow 1999).

Para atingir patamar de rendimento econômico desejável, nos diferentes ambientes em que o feijoeiro é cultivado, torna-se importante a compreensão dos processos que afetam o crescimento e desenvolvimento da planta e que, consequentemente, influenciam no rendimento da cultura (Urchei et al. 2000).

Diante do exposto, este estudo objetivou comparar duas cultivares de feijoeiro (BRS Radiante e Pérola), contrastantes no ciclo e hábito de crescimento, por meio de índices morfofisiológicos e eficiência de uso da radiação solar.

\section{MATERIAL E MÉTODOS}

Cultivares de feijoeiro Pérola e BRS Radiante foram semeadas em área experimental $\left(16^{\circ} 28^{\prime} 00^{\prime \prime} \mathrm{S}\right.$, $49^{\circ} 17^{\prime} 00^{\prime \prime} \mathrm{W}$ e altitude de $\left.823 \mathrm{~m}\right)$, em seis datas: $15 / 06$ e 29/06, em 2011; e 23/04, 22/05, 08/06 e 20/06, em 2012. Essas datas representam a época de produção do feijoeiro comum no Brasil denominada outono/ inverno.

A variação nas temperaturas máxima e mínima do ar e na radiação solar global, durante o período experimental, obtidas na estação meteorológica automática da Embrapa Arroz e Feijão, em Santo Antônio de Goiás (GO), situada a cerca de $60 \mathrm{~m}$ da área experimental, está apresentada na Figura 1.

A cultivar Pérola possui hábito de crescimento indeterminado (tipo III) e ciclo médio de 90 dias e a cultivar BRS Radiante possui hábito de crescimento determinado (tipo I) e ciclo médio de 75 dias (Embrapa 2012). Em cada data de semeadura, as cultivares foram semeadas em quatro parcelas de $67,5 \mathrm{~m}^{2}$, constituídas de 15 linhas, com $10 \mathrm{~m}$ de comprimento, espaçadas em $0,45 \mathrm{~m}$. A semeadura foi feita no sistema plantio direto, com 12 sementes $\mathrm{m}^{-1}$.

$\mathrm{O}$ solo da área experimental é classificado como Latossolo Vermelho distrófico, cuja camada superficial $(0-20 \mathrm{~cm})$ apresentou as seguintes características físicas e químicas: textura argilosa; $1,5 \mathrm{Mg} \mathrm{m}^{-3}$ de densidade do solo; 6,0 de $\mathrm{pH}\left(\mathrm{H}_{2} \mathrm{O}\right) ; 17 \mathrm{~g} \mathrm{dm}^{-3}$ de matéria orgânica; $5,7 \mathrm{mg} \mathrm{dm}^{-3} \mathrm{de} \mathrm{P} ; 0,2 \mathrm{cmol}_{\mathrm{c}} \mathrm{dm}^{-3}$ de $\mathrm{K} ; 2,1 \mathrm{cmol} \mathrm{dm}^{-3}$ de $\mathrm{Ca}$; 0,9 $\mathrm{cmol}_{\mathrm{c}} \mathrm{dm}^{-3} \mathrm{de} \mathrm{Mg}$; $3,9 \mathrm{cmol}_{\mathrm{c}} \mathrm{dm}^{-3} \mathrm{de}$ acidez potencial; $6,4 \mathrm{cmol}_{\mathrm{c}} \mathrm{dm}^{-3} \mathrm{de}$ CTC a pH 7; e saturação por bases de $50 \%$.

As adubações de base e de cobertura foram semelhantes em todas as épocas de semeadura, sendo aplicados, na base, $20 \mathrm{~kg} \mathrm{ha}^{-1}$ de N, $120 \mathrm{~kg} \mathrm{ha}^{-1}$ de P e $60 \mathrm{~kg} \mathrm{ha}^{-1}$ de K. Foram efetuadas duas adubações

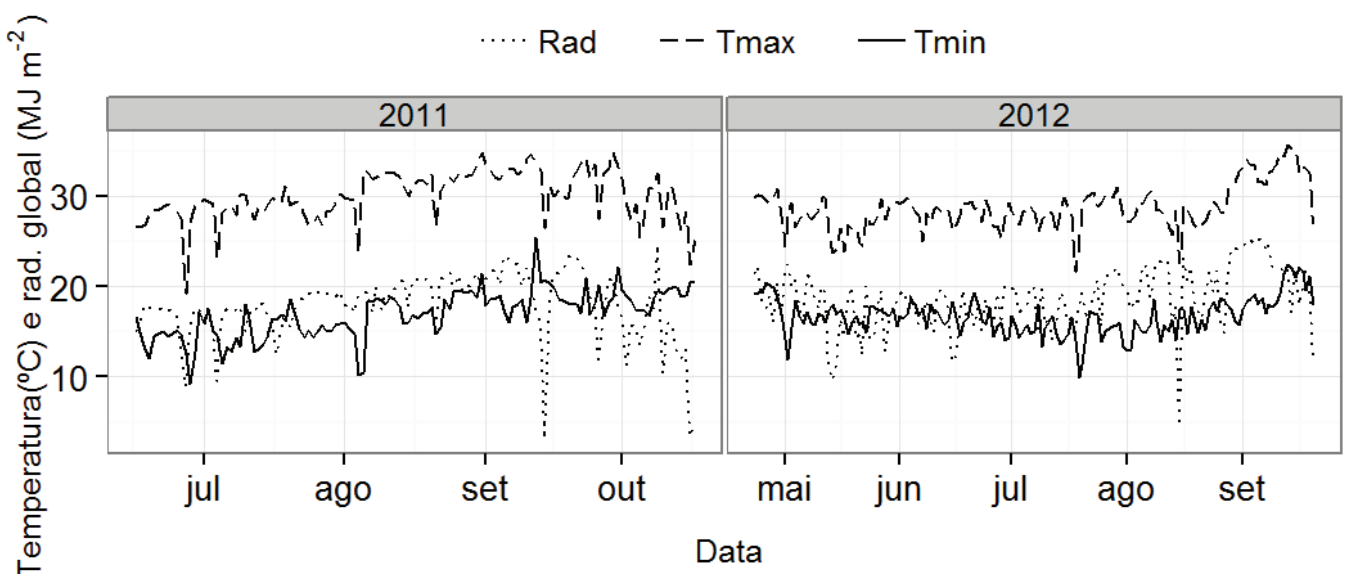

Figura 1. Temperaturas máximas, mínimas e radiação solar global durante a condução dos experimentos (Santo Antônio de Goiás, GO, 2011 e 2012). 
de cobertura: no início do estádio V3 (primeira folha trifoliolada com folíolos completamente expandidos), com $30 \mathrm{~kg} \mathrm{ha}^{-1}$ de N; e no final do estádio V4 (três folhas trifolioladas com folíolos totalmente expandidos), com $50 \mathrm{~kg} \mathrm{ha}^{-1}$ de $\mathrm{N}$ e $30 \mathrm{~kg} \mathrm{ha}^{-1}$ de $\mathrm{K}_{2} \mathrm{O}$.

$\mathrm{O}$ experimento foi conduzido de forma a minimizar os efeitos dos estresses abióticos e bióticos. A irrigação foi efetuada por meio de um sistema convencional de aspersão e seu manejo por meio de baterias de tensiômetro, a $15 \mathrm{~cm}$ de profundidade, irrigando quando a tensão da água no solo atingia $30 \mathrm{kPa}$.

As fases fenológicas após a emergência (EM), V4, R1 (primeira flor aberta), R3 (vagens com até $1 \mathrm{~cm}$ de comprimento), R5 (vagens com 3-4 cm, com as sementes perceptíveis), R7 (vagens completamente desenvolvidas, contudo, com as sementes ainda verdes) e R8 (80 \% das vagens em maturação fisiológica) foram observadas no campo, segundo tabela proposta por Kandel (2013).

Durante o ciclo de desenvolvimento, foram coletadas, semanalmente, em cada parcela, cinco plantas por metro, as quais foram separadas em caules, folhas e vagens. Esse material foi seco em estufa a $75^{\circ} \mathrm{C}$, por 48 horas, e pesado, para a obtenção de sua massa de matéria seca total (MST). A área foliar foi determinada por meio de medidor fotoelétrico (LI-COR - LI-3100).

A radiação fotossinteticamente ativa (RFA, 400-700 nm) foi medida entre as linhas da cultura, abaixo e no topo do dossel, em todas as parcelas, entre os estádios V4 e R8, com o auxílio de um sensor (LI-COR-LI 191Line Quantum). A fração da radiação fotossinteticamente ativa interceptada pelo dossel da cultura (RFAi) foi calculada e transformada em $\mathrm{MJ} \mathrm{m}^{-2} \mathrm{~d}^{-1}$, assumindo-se que a radiação fotossinteticamente ativa corresponde a $50 \%$ da radiação solar global diária incidente média, no período compreendido entre os estádios. A radiação solar global e as temperaturas do ar máximas e mínimas diárias necessárias para o cálculo dos graus-dia, no período de experimentação, foram coletadas em estação meteorológica situada a cerca de $60 \mathrm{~m}$ da área experimental.

Os índices fisiológicos foram obtidos com base na análise do conjunto de dados composto das seis datas de semeadura.

O coeficiente de extinção de luz ( $\mathrm{k}$ ) foi calculado para ambas as cultivares, utilizando-se a seguinte equação não linear:

$$
\mathrm{I} / \mathrm{Io}=[1-\exp (-\mathrm{k} * \mathrm{IAF})]
$$

sendo I e Io valores de irradiância abaixo e acima do dossel e índice de área foliar. A eficiência do uso da radiação (EUR, $\mathrm{g} \mathrm{MJ}^{-1}$ ) foi obtida por meio do coeficiente angular da regressão linear entre a massa de matéria seca total acumulada $\left(\mathrm{g} \mathrm{m}^{-2}\right)$ e a radiação fotossinteticamente ativa acumulada (RFA, $\mathrm{MJ} \mathrm{m}^{-2}$ ).

A matéria seca total, durante o ciclo das cultivares, foi ajustada aos valores de graus-dia acumulados, por meio do seguinte modelo logístico:

$$
\operatorname{MST}=a /\left[1+\left(b * \exp ^{(\mathrm{cx})}\right]\right.
$$

sendo $\mathrm{a}, \mathrm{b}, \mathrm{c}$ valores do parâmetro relativo à assíntota, inflexão e escala, respectivamente, e x o tempo de desenvolvimento em graus-dia acumulado (GDA, ${ }^{\circ} \mathrm{C}$ ), após a emergência. Para o cálculo do GDA, considerou-se a seguinte equação:

$$
\mathrm{GDA}=\sum_{\mathrm{i}=1}^{\mathrm{n}}\left(\frac{\mathrm{Tmax}-\mathrm{Tmin}}{2}-\mathrm{Tb}\right)
$$

em que a temperatura basal mínima (Tb) de crescimento considerada foi de $10{ }^{\circ} \mathrm{C}$ (Manfron et al. 1993). Tmax e Tmin correspondem à temperatura do ar diária máxima e mínima, em ${ }^{\circ} \mathrm{C}$.

$\mathrm{O}$ índice de área foliar (IAF), durante o ciclo das cultivares, foi ajustado aos valores de graus-dia acumulados por meio do modelo exponencial polinomial de $2^{\circ}$ grau:

$$
\mathrm{IAF}=\mathrm{a} * \exp \left(\mathrm{b} * \mathrm{x}-\mathrm{c} * \mathrm{x}^{2}\right)
$$

sendo a, b e c parâmetros empíricos de ajuste da equação e x-GDA.

A partir dessas funções, foram derivadas as taxas de crescimento da cultura (TCC) e de crescimento relativo (TCR):

$$
\mathrm{TCC}=(\mathrm{c} / \mathrm{a}) * \operatorname{MST} *(\mathrm{a}-\mathrm{MST})
$$

sendo a e c valores do parâmetro relativo à assíntota e escala da equação 2 ;

$$
\mathrm{TCR}=\mathrm{TCC} / \mathrm{MST}
$$

A partição de matéria seca foi obtida a partir da massa de matéria seca dos órgãos, folhas (MSF), caules (MSC) e vagens (MSV), em função da MST:

$$
\begin{aligned}
& \mathrm{MSF}=\mathrm{MSF} / \mathrm{MST} \\
& \mathrm{MSC}=\mathrm{MSC} / \mathrm{MST} \\
& \mathrm{MSV}=\mathrm{MSV} / \mathrm{MST}
\end{aligned}
$$


Os dados de matéria seca das folhas e do caule, em função dos graus-dia acumulados, foram ajustados pelo modelo exponencial polinomial de $2^{\circ}$ grau, e os de massa de matéria seca das vagens pelo modelo logístico. Para a comparação dos coeficientes de extinção de luz obtidos para cada cultivar, utilizou-se o método de verossimilhança.

\section{RESULTADOS E DISCUSSÃO}

Em razão do seu ciclo precoce, a cultivar BRS Radiante apresentou menor exigência térmica que a Pérola, para atingir todos os estádios fenológicos (Figura 2). Ela apresentou desenvolvimento vegetativo mais rápido, com o acúmulo de 207,3 graus-dia entre a emergência e o estádio V4, enquanto a cultivar Pérola necessitou de 249,1 graus-dia. Contudo, a BRS Radiante apresentou maior acúmulo térmico no período de enchimento de grãos, compreendido entre os estádios R5 e R7 (Figura 2b).

Cultivares de hábito de crescimento indeterminado, a exemplo da cultivar Pérola, apresentam desenvolvimento vegetativo durante seu estádio reprodutivo, ou seja, sobreposição das fases de desenvolvimento, o que interfere na relação fonte-dreno, acarretando em mudança na distribuição de assimilados na planta (Bezerra et al. 2009). Essa característica pode ter contribuído para a redução da necessidade térmica da cultivar Pérola, durante a fase de enchimento de grãos, quando comparada com a BRS Radiante.
Resultados semelhantes também foram observados por Moura et al. (2012), os quais relatam que os distintos hábitos de crescimento e ciclo das cultivares são responsáveis pela diferença de necessidade térmica entre seus estádios fenológicos. O feijão-caupi (Vigna unguiculata L.) apresentou maior necessidade térmica para o desenvolvimento da fase vegetativa, em relação à fase reprodutiva, característica geralmente observada em cultivares de crescimento indeterminado.

A evolução do índice de área foliar no tempo seguiu o padrão característico de plantas anuais (Figura 3a). A cultivar BRS Radiante apresentou índice de área foliar máximo $(4,5)$, concomitantemente ao acúmulo termal de 550 graus-dia, entre os estádios R5 e R7. Para a cultivar Pérola, o maior valor de índice de área foliar foi de 3,7, com acúmulo termal de 711 graus-dia, entre os estádios R3 e R5. A cultivar BRS Radiante, apesar de ser classificada como de crescimento determinado, obteve o maior valor para índice de área foliar após o estádio R1. Isso demonstra que ela continua emitindo folhas nos ramos laterais, após o florescimento. Considerando-se que as condições edafoclimáticas foram semelhantes para as duas cultivares, pode-se afirmar que a diferença entre estádios para atingir o índice de área foliar máximo foi devido, estritamente, a fatores genotípicos (Gonzalez et al. 2010). A cultivar Pérola possui maior número de ramificações e enfolhamento, contudo, a BRS Radiante apresenta folhas maiores, sendo essa uma das características responsáveis pelo seu maior índice de área foliar.

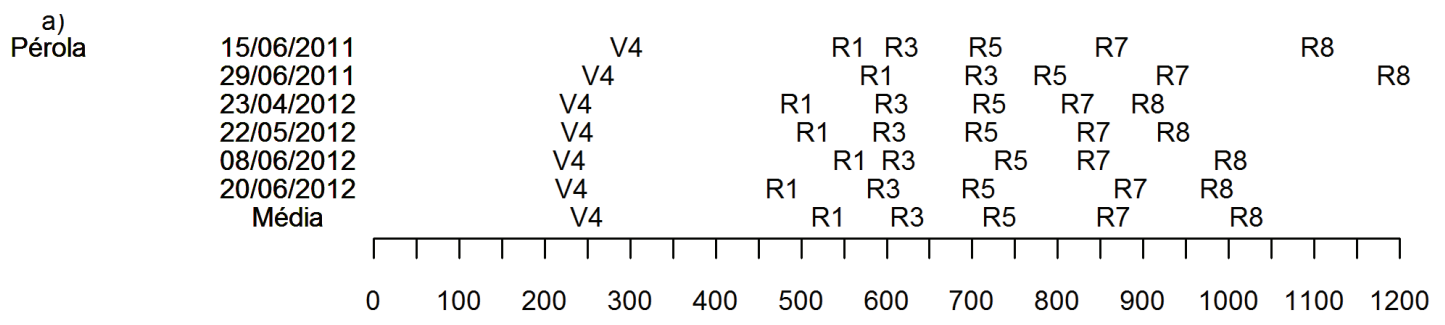

b)

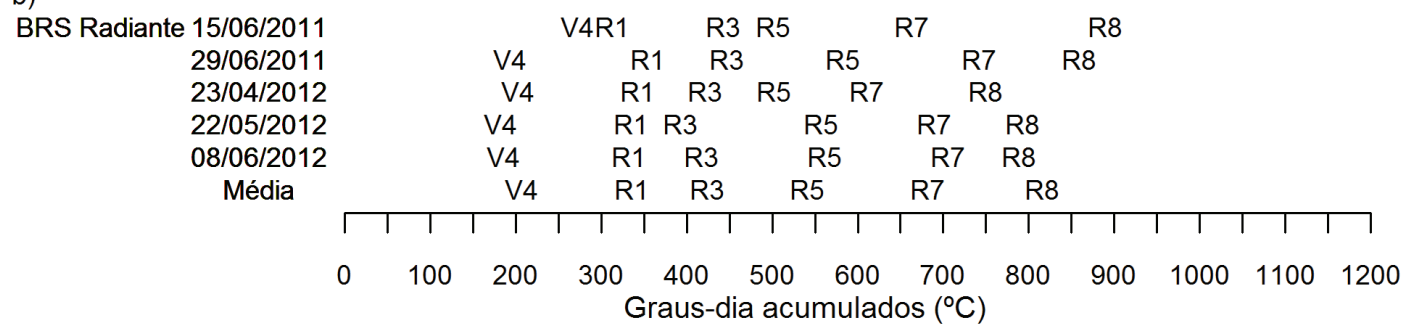

Figura 2. Fenologia, em razão do somatório de graus-dia, para as cultivares Pérola (a) e BRS Radiante (b), na safra outono/inverno (Santo Antônio de Goiás, GO, 2011 e 2012). 

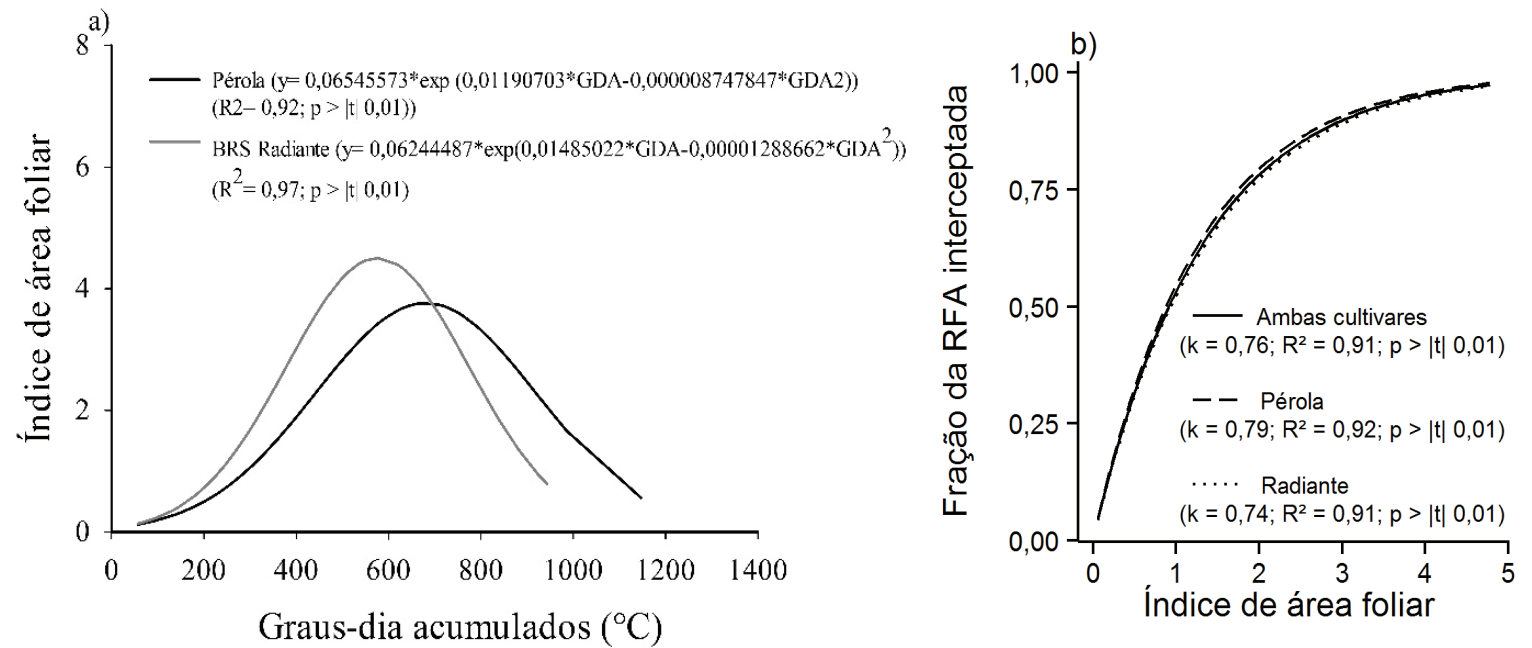

Figura 3. Índice de área foliar (IAF), em função do somatório de graus-dia (a), e fração da radiação fotossinteticamente ativa (RFA) interceptada, em função do IAF (b), das cultivares Pérola e BRS Radiante, na safra outono/inverno (Santo Antônio de Goiás, GO, 2011 e 2012).

Em Santa Maria, Jauer et al. (2003) constataram que o índice de área foliar máximo da cultivar Pérola foi atingido próximo ao estádio R5, o que está de acordo com o verificado neste trabalho e é típico de cultivares de hábito indeterminado. Contudo, o valor máximo de índice de área foliar obtido por esses autores $(6,7)$ foi bem superior ao encontrado neste trabalho, o que se deve, possivelmente, às diferenças climáticas e de manejo, na condução da cultura.

A interceptação da radiação por uma superfície é influenciada pelo seu tamanho, forma, ângulo de inserção e orientação azimutal, separação vertical e arranjo horizontal e pela absorção por estruturas não foliares (Lucchesi 1984). O ângulo foliar é um parâmetro importante na produção, já que folhas eretas são mais eficientes para a fotossíntese máxima, para valores maiores de índice de área foliar.

$\mathrm{O}$ incremento no índice de área foliar aumenta a produção de massa de matéria seca, mas, devido ao autossombreamento das folhas, a taxa fotossintética média por unidade de área foliar decresce. À medida que o índice de área foliar aumenta, as folhas inferiores são mais sombreadas e, consequentemente, a taxa fotossintética média de toda a área foliar é diminuída (Zabot et al. 2004).

O coeficiente de extinção de luz (k), erro padrão e $\mathrm{R}^{2}$ obtidos para as cultivares Pérola e BRS Radiante foram, respectivamente, de 0,79; 0,033; 0,92 e 0,$74 ; 0,024 ; 0,91$ (Figura 3b). Por meio do método de verossimilhança, verificou-se que não houve diferença entre elas, podendo ser adotado, dessa forma, o valor de $\mathrm{k}=0,76$, com erro padrão $=$ 0,020 e $\mathrm{R}^{2}=0,91$, para ambas as cultivares, obtido por meio de análise conjunta. Verifica-se que a diferença entre as cultivares, em relação à arquitetura da parte aérea, deve ter compensado o maior índice de área foliar da cultivar BRS Radiante, resultando em similar valor de $\mathrm{k}$.

Neste estudo, o valor de $k$ obtido foi maior que os encontrados por Procópio et al. (2003) (0,69 para a cultivar Pérola) e Tsubo et al. (2001) (0,64 para a cultivar PAN 127, de crescimento determinado), sendo ambos os experimentos conduzidos na safra das "águas", mas menor que o encontrado por Tesfaye et al. (2006) (0,84 para a cultivar Roba-1, na ausência de défice hídrico).

O coeficiente de extinção de luz varia de acordo com mudanças no ambiente, tais como ocorrência de deficiência hídrica e época de semeadura (Tesfaye et al. 2006). Ele é função do tamanho e orientação das folhas. Valores de k elevados representam cultivares com arquitetura foliar que tendem a horizontal (planófila), com distribuição uniforme da área foliar, características que favorecem a redução da quantidade de luz incidente ao longo do perfil do dossel da planta (Ruiz \& Bertero 2008).

Durante o seu desenvolvimento, a cultivar BRS Radiante apresentou massa de matéria seca total superior à da Pérola (Figura 4a), devido ao fato de ter maior índice de área foliar e início de formação de vagens mais precoce, em relação à Pérola. Contudo, a cultivar Pérola apresenta maior duração do ciclo e hábito de crescimen- 

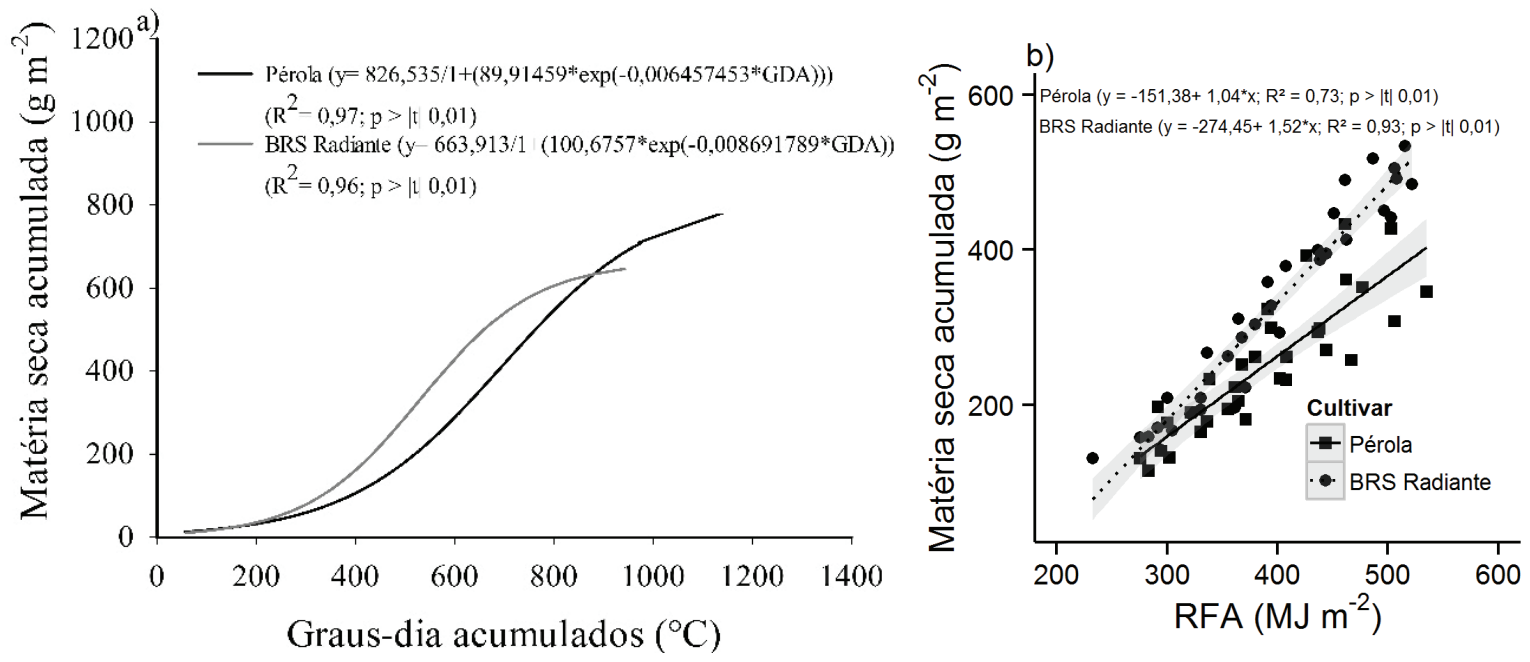

Figura 4. Produção de matéria seca acumulada, em função do somatório de graus-dia (a) e da radiação fotossinteticamente ativa (RFA) acumulada (b), referente às cultivares Pérola e BRS Radiante, na safra outono/inverno (Santo Antônio de Goiás, GO, 2011 e 2012). A faixa cinza indica o intervalo de confiança a 95\%, para a regressão linear.

to indeterminado, com maior número de ramificações e grãos (Embrapa 2012), características que contribuíram para a maior produção de massa de matéria seca total no final do ciclo, em relação à BRS Radiante.

A produção de massa de matéria seca total da cultivar Pérola foi de $784 \mathrm{~g} \mathrm{~m}^{-2}$, obtida com o acúmulo de 1.147 graus-dia, enquanto a da BRS Radiante foi de $646 \mathrm{~g} \mathrm{~m}^{-2}$, com acúmulo termal de 943 graus-dia. Os valores de massa de matéria seca total obtidos no final do ciclo situaram-se próximos aos observados por Gomes et al. (2000), que, avaliando o acúmulo de massa de matéria seca produzida por cultivares de feijão Xodó e A320, de crescimento indeterminado, encontraram valores de $580 \mathrm{~g} \mathrm{~m}^{-2}$ e $600 \mathrm{~g} \mathrm{~m}^{-2}$, respectivamente, e aos obtidos por Jauer et al. (2003), para a cultivar Pérola (cerca de $693 \mathrm{~g} \mathrm{~m}^{-2}$ ).

Apesar de as cultivares não diferirem quanto ao coeficiente $\mathrm{k}$, elas diferiram quanto à eficiência no uso da radiação, ou seja, em destinar seus fotoassimilados para a produção de biomassa, com o acúmulo da radiação fotossinteticamente ativa. A maior eficiência do uso da radiação foi obtida pela cultivar BRS Radiante $\left(1,52 \mathrm{~g} \mathrm{MJ}^{-1}\right.$; erro padrão $=0,07 ; \mathrm{R}^{2}=$ $0,93)$, quando comparada à Pérola $\left(1,04 \mathrm{~g} \mathrm{MJ}^{-1}\right.$; erro padrão $\left.=0,111 ; R^{2}=0,73\right)$ (Figura $\left.4 b\right)$. A superioridade da eficiência do uso da radiação apresentada pela BRS Radiante, possivelmente, não se deve a diferenças no índice de área foliar, em relação à cultivar Pérola, já que esse índice pouco afeta a eficiência do uso da radiação, mas sim ao seu porte mais ereto, possibilitando maior taxa fotossintética, que é a variável que mais afeta a eficiência do uso da radiação (Sinclair \& Muchow 1999).

Os valores obtidos para a eficiência do uso da radiação, neste estudo, foram inferiores aos encontrados por Santos et al. (2003), ao avaliarem a captação e o aproveitamento da radiação solar pelo feijoeiro, na safra das águas, na qual obtiveram eficiência do uso da radiação de $1,96 \mathrm{~g} \mathrm{MJ}^{-1}$ e $1,83 \mathrm{~g} \mathrm{MJ}^{-1}$, respectivamente antes e após o florescimento, e aos observados por Tesfaye et al. (2006), que, estudando a eficiência do uso da radiação sob três regimes hídricos, verificaram, na ausência de estresse hídrico, que a eficiência do uso da radiação pelo feijoeiro foi de 2,44 $\mathrm{g} \mathrm{MJ}^{-1}$. Essa diferença pode ser explicada pelos fatores genéticos e manejo da cultura, nos experimentos realizados pelos respectivos autores.

A partição da biomassa acumulada para a folha não diferiu entre as duas cultivares (Figura 5). Em ambas as cultivares, a fração de carboidratos na folha começa a se reduzir a partir do estádio R1. Para o caule, a cultivar Pérola apresenta incremento no acúmulo de carboidratos, no estádio R5, de $40 \%$ para $50 \%$. Já para a cultivar BRS Radiante, esse acúmulo não é acentuado.

Conforme mencionado anteriormente, o estádio R5 é caracterizado por apresentar vagens com 3-4 cm, com as sementes já perceptíveis. Em condições de estresse, esse acúmulo de carboidratos no caule pode ocasionar competição por assimilados, com o enchimento das vagens, pois, no estádio R5, para ambas as cultivares, inicia-se a fase linear para 

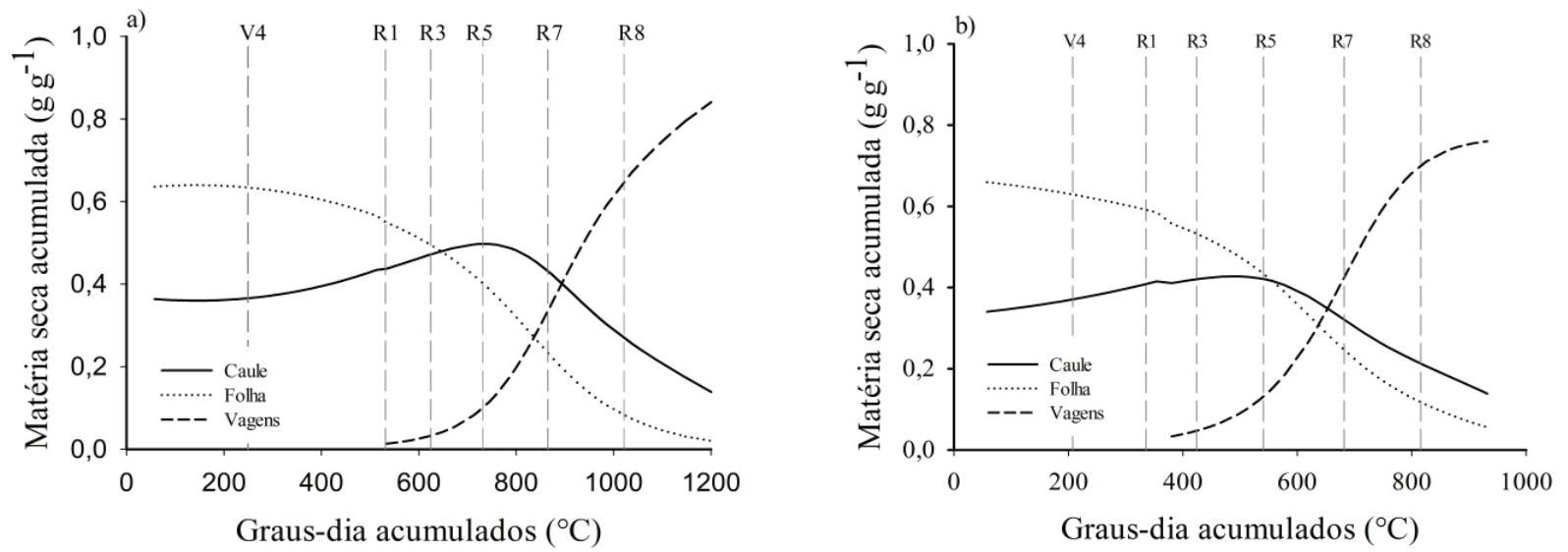

Figura 5. Partição da biomassa das cultivares Pérola (a) e BRS Radiante (b), em razão do somatório de graus-dia e estádios fenológicos (Santo Antônio de Goiás, GO, 2011 e 2012).

o enchimento de vagens. A cultivar Pérola iniciou a formação de vagens aos 531,4 graus-dia e a BRS Radiante aos 335,4 graus-dia. A máxima produção de vagens foi observada com o acúmulo termal de 1.147 graus-dia, para a cultivar Pérola, e aos 943 graus-dia, para a BRS Radiante (Figuras 5a e 5b).

Segundo Gomes et al. (2000), o acúmulo preferencial de massa de matéria seca ocorre nas folhas, depois no caule, seguindo-se as vagens, de acordo com a tendência de translocação. Concorre, também, para isso, a intensificação da senescência de folhas, a partir do florescimento.

$\mathrm{O}$ valor máximo da taxa de crescimento da cultura foi de $1,44 \mathrm{~g} \mathrm{~m}^{-2}{ }^{\circ} \mathrm{C}^{-1}$, para a BRS Radiante, e de $1,33 \mathrm{~g} \mathrm{~m}^{-2}{ }^{\circ} \mathrm{C}^{-1}$, para a cultivar Pérola, alcançados aos 550 e 711 graus-dia, respectivamente (Figura 6a). Esses valores corresponderam a cerca de $14 \mathrm{~g} \mathrm{~m}^{-2} \mathrm{~d}^{-1}$, para ambas as cultivares. A redução na taxa de crescimento da cultura, após esse estádio, é devida à translocação de fotoassimilados. A taxa de crescimento da cultura máxima, para ambas as cultivares, ocorreu no mesmo tempo termal que o máximo índice de área foliar.

Urchei et al. (2000) também observaram que a taxa de crescimento da cultura apresentou comportamento similar ao índice de área foliar. Medeiros et al. (2000) encontraram valor médio da taxa de crescimento da cultura de $11,4 \mathrm{~g} \mathrm{~m}^{-2} \mathrm{~d}^{-1}$, correspondendo a $0,62 \mathrm{~g} \mathrm{~m}^{-2}{ }^{\circ} \mathrm{C}^{-1}$, para populações de feijoeiros da cultivar Carioca 80-SH (crescimento indeterminado) de 14 plantas $\mathrm{m}^{-2}$ e 28 plantas $\mathrm{m}^{-2}$, com acúmulo termal entre 300 e 1.170 graus-dia, enquanto Jauer et al. (2003) obtiveram valor máximo de taxa de crescimento da cultura, para a cultivar Pérola, de $15,1 \mathrm{~g} \mathrm{~m}^{-2} \mathrm{~d}^{-1}$.


Figura 6. Taxa de crescimento da cultura (a) e taxa de crescimento relativo (b), em razão do somatório de graus-dia referentes às cultivares Pérola e BRS Radiante (Santo Antônio de Goiás, GO, 2011 e 2012). 
A BRS Radiante apresentou maior taxa inicial de crescimento relativo $\left(0,0086 \mathrm{~g} \mathrm{~g}^{-1}{ }^{\circ} \mathrm{C}^{-1}\right.$, contra $0,0066 \mathrm{~g} \mathrm{~g} \mathrm{~g}^{-1}{ }^{\circ} \mathrm{C}^{-1}$ da cultivar Pérola) (Figura 6b), perdurando a maior taxa de crescimento relativo até o acúmulo de 432 graus-dia, estádio R3, o que pode ser atribuído ao fato de a BRS Radiante apresentar crescimento inicial mais vigoroso. Jauer et al. (2003) obtiveram taxa de crescimento relativo máximo para a cultivar Pérola de $0,075 \mathrm{~g} \mathrm{~g}^{-1} \mathrm{~d}^{-1}$.

A taxa de crescimento relativo de um vegetal evidencia perfeitamente o seu crescimento, que é dependente do material que está sendo acumulado. A taxa de crescimento relativo geralmente diminui à medida que a planta cresce, em virtude do autossombreamento das folhas e pela produção de órgãos não fotossintetizantes. Cultivares mais produtivas, em geral, são as que crescem mais rapidamente. Verifica-se que plantas com maior taxa de crescimento relativo, geralmente, são também as que desenvolvem mais rapidamente o seu índice de área foliar (Lucchesi 1984), como ocorre com a BRS Radiante. Portanto, a taxa de crescimento relativo exerce maior influência durante a fase de desenvolvimento da área foliar. Quando alcança um índice de área foliar relativamente elevado, a correlação entre taxa de crescimento relativo e produtividade econômica se reduz.

\section{CONCLUSÕES}

1. A cultivar BRS Radiante apresenta maior vigor, quando comparada à cultivar Pérola, devido ao desenvolvimento fenológico inicial mais rápido e maiores taxas de crescimento inicial e relativo.

2. As cultivares não diferem quanto ao coeficiente de extinção de luz, embora apresentem diferença quanto ao índice de área foliar e arquitetura da parte aérea.

3. A cultivar BRS Radiante apresenta maior eficiência de uso da radiação solar, resultando em maior produção de matéria seca ao longo do seu desenvolvimento.

\section{REFERÊNCIAS}

BEZERRA, A. A. C. et al. Características de dossel e de rendimento em feijão-caupi ereto em diferentes densidades populacionais. Pesquisa Agropecuária Brasileira, Brasília, DF, v. 44, n. 10, p. 1239-1245, 2009.

EMPRESA BRASILEIRA DE PESQUISA AGROPECUÁRIA (Embrapa). Catálogos de cultivares de feijão-comum. 2012. Disponível em: < http://www. cnpaf.embrapa.br/transferencia/tecnologiaseprodutos/ cultivares/cultivaresFeijao-28Setembro2012.pdf $>$. Acesso em: 31 mai. 2013.

FAGUNDES, J. L. et al. Índice de área foliar, coeficiente de extinção luminosa e acúmulo de forragem em pastagens de Cynodon ssp. Pesquisa Agropecuária Brasileira, Brasília, DF, v. 36, n. 1, p. 187-195, 2001.

GOMES, A. A. et al. Acumulação de biomassa, características fisiológicas e rendimento de grãos em cultivares de feijoeiro irrigado e sob sequeiro. Pesquisa Agropecuária Brasileira, Brasília, DF, v. 35, n. 10, p. 1927 1937, 2000.

GONZALEZ, N. et al. Increased leaf size: different means to an end. Plant Physiology, Rockville, v. 153, n. 3, p. 1261-1279, 2010.

JAUER, A. et al. Análise de crescimento da cultivar de feijão Pérola em quatro densidades de semeadura. Revista da FZVA, Uruguaiana, v. 10, n. 1, p. 1-12, 2003.

KANDEL, H. (Ed.). Dry bean production guide. 2013. Disponível em: <http://www.ag.ndsu.edu/pubs/plantsci/ rowcrops/a1133a.pdf>. Acesso em: 25 mai. 2013.

LUCCHESI, A. A. Utilização prática da análise de crescimento vegetal. Anais da Escola Superior de Agricultura Luiz de Queiroz, Piracicaba, v. 41, n. 1, p. 181-202, 1984.

MANFRON, P. A.; LAZZAROTO, C.; MEDEIROS, S. L. P. Trigo: aspectos agrometeorológicos. Revista do Centro de Ciências Rurais, Santa Maria, v. 23, n. 2, p. 237-239, 1993.

MEDEIROS, G. A. et al. Crescimento vegetativo e coeficiente de cultura do feijoeiro relacionados a graus-dia acumulados. Pesquisa Agropecuária Brasileira, Brasília, DF, v. 35, n. 9, p. 1733-1742, 2000.

MOURA, J. Z. et al. Escala de desenvolvimento fenológico e exigência térmica associada a graus-dia do feijão-caupi. Revista Caatinga, Mossoró, v. 25, n. 3, p. 66-71, 2012.

PEREIRA, V. G. et al. Exigências agroclimáticas para a cultura do feijão (Phaseolus vulgaris L.). Revista Brasileira de Energias Renováveis, Cascavel, v. 3, n. 1, p. 32-42, 2014.

PROCÓPIO, S. O. et al. Desenvolvimento foliar das culturas da soja e do feijão e de plantas daninhas. Ciência Rural, Santa Maria, v. 33, n. 2, p. 207- 211, 2003.

RUIZ, R. A.; BERTERO, H. D. Light interception and radiation use efficiency in temperate quinoa (Chenopodium quinoa Willd.) cultivars. European Journal of Agronomy, Copenhagen, v. 29, n. 1, p. 144-152, 2008. 
SANTOS, J. B. et al. Captação e aproveitamento da radiação solar pelas culturas da soja e do feijão e por plantas daninhas. Bragantia, Campinas, v. 62, n. 1, p. 147153, 2003.

SINCLAIR, T. R.; MUCHOW, R. C. Radiation use efficiency. Advances in Agronomy, San Diego, v. 65, n. 2, p. 215-265, 1999.

TESFAYE, K.; WALKER, S.; TSUBO, M. Radiation interception and radiation use efficiency of three grain legumes under water deficit conditions in a semiarid environment. European Journal of Agronomy, Copenhagen, v. 25, n. 1, p. 60-70, 2006.
TSUBO, M.; WALKER, S.; MUKHALA, E. Comparisons of radiation use efficiency of mono-/inter-cropping systems with different row orientations. Field Crops Research, Amsterdam, v. 71, n. 1, p. 17-29, 2001.

URCHEI, M. A.; RODRIGUES, J. D.; STONE, L. F. Análise de crescimento de duas cultivares de feijoeiro sob irrigação, em plantio direto e preparo convencional. Pesquisa Agropecuária Brasileira, Brasília, DF, v. 35, n. 3, p. 497-506, 2000.

ZABOT, L. et al. Análise de crescimento da cultivar de feijão BR IPAGRO 44 Guapo Brilhante cultivada na safrinha, em quatro densidades de semeadura, em Santa Maria/RS. Revista de Ciências Agroveterinárias, Lages, v. 3, n. 2, p. 105-115, 2004. 